\title{
Implementasi Metode Seismik Inversi Impedansi Akustik dalam Memetakan Batuan Pasir dengan Pengoptimasian Parameter error dan Korelasi Serta Mentransformasikan Penyebaran Porositas
}

\begin{tabular}{l}
\hline Received \\
05 April 2017 \\
Revised \\
05 Juni 2017 \\
Accepted for Publication \\
08 Juni 2017 \\
Published \\
20 November 2017 \\
\hline
\end{tabular}

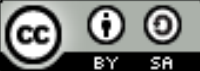

This work is licensed under a Creative Commons Attributio ShareAlike 4.0 International License.

\author{
N F Isniarno ${ }^{1^{*}}$, W Triyoso $^{2}$, R Amukti $^{1}$ \\ 1. Jurusan Teknik Pertambangan, Fakultas Teknik, Universitas Islam Bandung, Indonesia \\ 2. Jurusan Teknik Geofisika, Fakultas Teknik Pertambangan dan Perminyakan, Institut Teknologi \\ Bandung, Indonesia \\ *E-mail: noor.fauzi@unisba.ac.id, noor_fauzi_isniarno@yahoo.com.
}

\begin{abstract}
In determining seismic inversion acoustic impedance, must be based on research and availability of data, so that will produce an impedance acoustic volume of the results of the selection of errors and the maximum correlation. The inverse seismic method is a technique for descripting qualitatively or quantitatively a reservoir by using seismic data so that it can be used for approximate geological models. This research was conducted with the aim of implementing the seismic inversion method of acoustic impedance in mapping sand rock by optimizing parameters and identifying porosity dispersion. In this research, the comparison of bandlimited inversion method, hard constraint based model, and soft constraint based model in producing acoustic impedance has the smallest error and correlation, so that the acoustic impedance volume will be obtained. The result of an acoustic impedance inversion is made crossplot between porosity with acoustic impedance. The relationship will produce a linear equation. This equation is used to transform the volume of the acoustic impedance into the porosity. Then compared to see the reservoir characteristics of the target zone. The study area has sand with acoustic impedance 16230 $20500 \mathrm{ft} / \mathrm{s} \mathrm{gr} / \mathrm{cm}^{3}$.
\end{abstract}

Keywords:Seismic Inversion, Acoustic Impedance, Porosity

\begin{abstract}
Abstrak
Dalam penentuan seismik inversi impedansi akustik, harus didasarkan berdasarkan penelitian dan ketersedian data, sehingga akan menghasilkan sebuah volum impedansi akustik dari hasil pemilihan eror dan korelasi yang paling maksimal. Metode seismik inversi adalah suatu teknik untuk mendeskripsi secara kualitatif atau kuantitaif suatu reservoir dengan menggunakan data seismik sehingga dapat digunakan untuk perkiraan model geologi. Pada penelitian ini dilakukan dengan tujuan mengimplementasikan metode seismik inversi impedansi akustik dalam memetakan batuan pasir dengan mengoptimasikan parameter dan mengidentifikasi penyebaran porositas. Dalam penelitian ini dilakukan perbandingan hasil metode inversi bandlimited, model based hard constraint, dan model based soft constraint dalam menghasilkan impedansi akustik yang memiliki eror yang paling kecil dan korelasi paling besar, sehingga akan didapatkan peta volum impedansi akustik. Hasil inversi impedansi akustik dibuat crossplot antara porositas dengan impedansi akustik. Hubungan tersebut akan menghasilkan sebuah persamaan linear. Persamaan ini yang dipergunakan untuk mentransformasikan volum impedansi akustik ke dalam porositas. Kemudian dibandingkan untuk melihat karakteristik reservoar zona target. Daerah penelitian memiliki sand dengan Impedansi akustik $16230-20500 \mathrm{ft} / \mathrm{s} \mathrm{gr} / \mathrm{cm}^{3}$.
\end{abstract}

Kata Kunci:Seismik Inversi, Impedansi akustik, Porositas.

\section{Pendahuluan}

Batuan reservoir adalah batuan dari kerak bumi yang memiliki karakter tertentu, pada dasarnya semua batuan penyusun kerak bumi dapat menjadi batuan reservoir asalkan mampu menyimpan fluida 
melalui rongga pori (porositas) yang dimilikinya serta mampu melepaskan dan mengalirkan fluida tersebut melalui konektivitas antar pori (permeabilitas) [1]. Jadi batuan reservoar merupakan batuan yang berfungsi sebagai tempat yang mampu terisi minyak dan gas bumi. Dua jenis data utama yang dipakai pada tahapan eksplorasi, eksploitasi maupun pengembangan adalah data log dan data seismic [2]. Data log yang sangat berkaitan dengan data seismik adalah log sonik dan densitas [3]. Masingmasing data tersebut mempunyai kekuatan dan kelemahan sendiri-sendiri. Penelitian untuk mengeksplorasi data kedua metode tersebut adalah hal penting agar kekuatannya teroptimalkan sedangkan kelemahannya diminimalkan [4].

Seismik inversi merupakan suatu teknik untuk membuat model geologi bawah permukaan dengan menggunakan data seismik sebagai input dan data sumur sebagai kontrol [5]. Seismik inversi dapat dinyatakan sebagai suatu pemodelan ke belakang, yaitu dengan menerapkan proses dekonvolusi data seismik terhadap wavelet yang selanjutnya akan dihasilkan sebuah penampang impedansi akustik. Metode seismik inversi dapat menurunkan nilai impedansi akustik tiap lapisan yang kemudian dapat digunakan untuk menyediakan interpretasi informasi geologi lebih lanjut.

Elaborasi untuk menentukan hasil inversi impedansi akustik yang paling baik adalah penting. Mengingat penentuan impedansi akustik secara inversi secara praktis belum memperhatikan optimasi nilai eror dan korelasi berdasarkan penelitian dan ketersedian data. Dengan demikian dilakukan penelitan yang bertujuan untuk melakukan optimalisasi parameter dan identifikasi penyebaran porositas berdasarkan hasil pengukuran.

\section{Metode Penelitian}

Seismik inversi dapat dikatakan sebagai pemodelan ke belakang, yaitu dengan menerapkan proses dekonvolusi data seismik terhadap wavelet yang selanjutnya akan dihasilkan sebuah penampang impedansi akustik [6].

$$
A I=\rho V,
$$

dengan $A I$ adalah Impedansi Akustik, $\rho$ merupakan densitas dan $V$ adalah kecepatan.

Impedansi akustik $(A I)$ didefinisikan sebagai kemampuan batuan untuk melewatkan gelombang sesismik yang melaluinya. Tiga parameter penting dari batuan yang memperngaruhi perilaku seismik adalah kecepatan, densitas dan impedansi akustik [7], pengolahan data dilakukan sesuai dengan tujuan dari penelitian ini.

Adapun tahapan-tahapan yang dilakukan dalam penelitian ini adalah sebagai berikut. Pengolahan yang dilakukan pada data log sumur bertujuan untuk mempersiapkan berbagai macam data log agar siap dipakai untuk proses Well to Seismic Tie dan pembuatan data pendukung interpretasi seperti crossplot antar log serta analisa tuning thickness[8]. Ini terlihat pada Gambar 1.

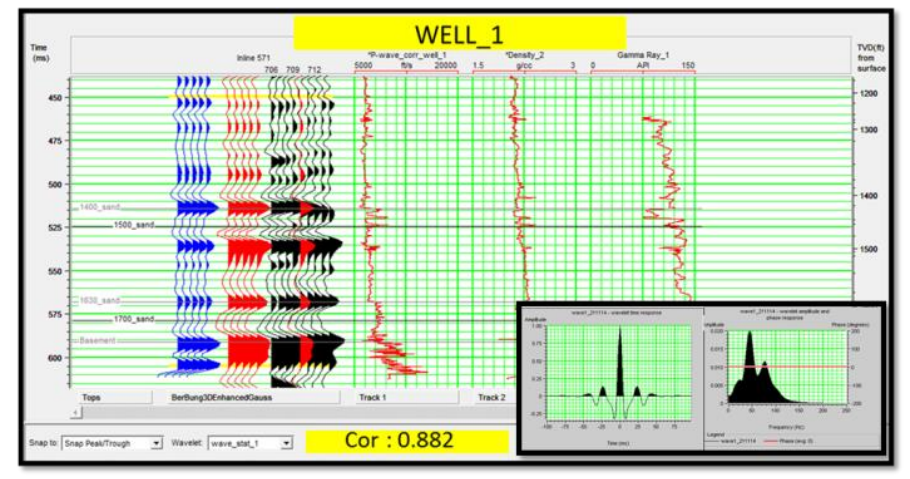

Gambar 1. Well to seismic tie dengan korelasi 0,882. 


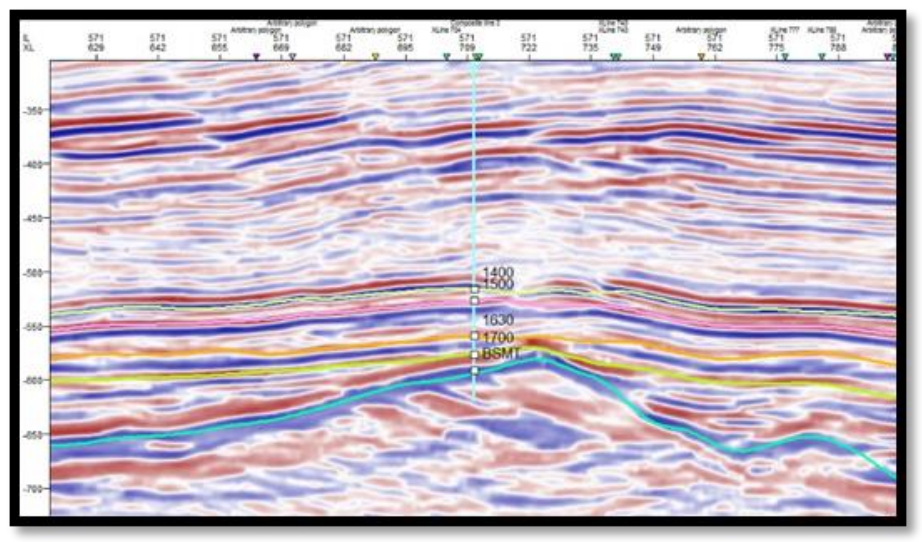

Gambar 2. Lima horizon yang dipergunakan dalam penelitian ini.

Spektrum amplitudo dilakukan pada TWT dekat dengan marker zona target. TWT batas adalah 450 - $600 \mathrm{~ms}$ yang berada pada marker 1400 dan basement. Ekstraksi wavelet dilakukan untuk mencari wavelet terbaik untuk korelasi sumur dan seismik. Setelah itulah dilakukan well to seismic tie. Untuk mencocokan antara seismogram sintetik dengan data seismik, dilakukan proses stretch and squeeze. Marker yang tersedia dari sumur adalah 1400, 1500, 1630, 1700 dan basement. Maka dilakukan picking horizon yang menghasilkan sebuah surface di setiap marker tersebut. Adapun hasil dari pengolahan data seismic dan sumur, dapat dilihat pada Gambar 2. Model awal dalam proses inversi diperlukan untuk mengontrol hasil inversi yang dilakukan selanjutnya. Model geologi ini dibuat dengan menggunakan data sumur dan horizon [3].

\section{Hasil dan Pembahasan}

Crossplot merupakan dasar parameter untuk menentukan metode apa yang dipakai lebih lanjut. Crosplot antara gamma ray dan p-impedance memperlihatkan harga AI dapat digunakan untuk memisahkan litologi antara sand dan shale [9]. Hasil crossplot dapat dilihat pada Gambar 3.

Untuk mengetahui hubungan yang sesuai antara impedansi akustik dengan porositas, maka nilai porositas yang digunakan haruslah nilai porositas efektif, dengan harapan porositas efektif mewakili nilai porositas yang sebenarnya. Nilai porositas efektif yang digunakan telah dipilah berdasarkan kesamaan trend antara porositas efektif dan porositas total. Hasil crossplot dengan AI terlihat pada Gambar 4.

Metode inversi seismik yang diterapkan pada penelitian ini dibatasi pada jenis inversi seismik bandlimited dan inversi seismik model-based. Dari hasil inversi bandlimited dan model-based Hard Constraint serta model-based Soft Constraint, maka hasil inversi model-based Hard Constraint menghasilkan impedansi yang paling baik dibandingkan dengan kedua jenis inversi lain yang dilihat dari hasi pengukuran optimasi parameter. Hasil dapat dilihat pada Tabel 1.

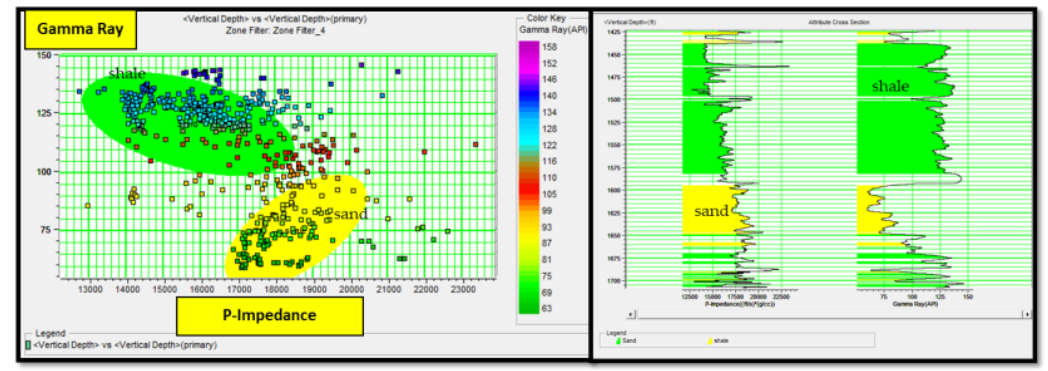

Gambar 3. Crossplot antara gamma-ray dan p-impedance dengan color key adalah gamma-ray. 


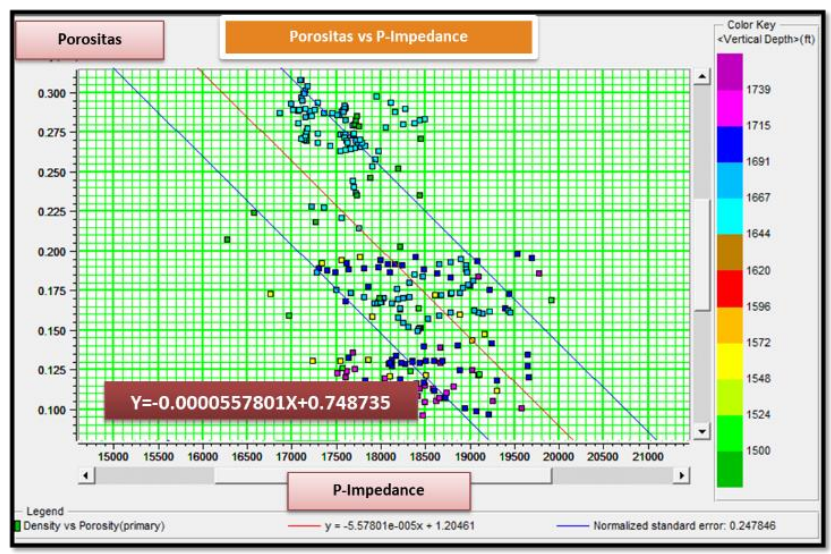

Gambar 4. Crossplot antara porositas dengan $A I$.

Tabel 1. Nilai error, corelation dan error sythentics \& seismic masing-masing jenis inversi seismik

\begin{tabular}{lccc}
\hline Jenis Inversi & Error & Correlation & Err. Synthetic \& Seismic \\
\hline Bandlimited & 2436,94 & 0,956279 & \\
Model Based Hard Constraint & 1476,45 & 0,971918 & 0,241797 \\
Model Based Soft Constraint & 1488,40 & 0,963722 & 0,281042 \\
\hline
\end{tabular}

Tabel 2. Nilai QC antara impedansi akustik hasil inversi dengan impedansi sumur.

\begin{tabular}{lcc}
\hline Jenis Inversi & Y=X & Least Square \\
\hline Bandlimited & $\mathrm{Y}=1,0555 \mathrm{X}+702,08$ & 0,632 \\
Model Based Hard Constraint & $\mathrm{Y}=1,0592 \mathrm{X}+568,41$ & 0,882 \\
Model Based Soft Constraint & $\mathrm{Y}=1,0294 \mathrm{X}+69,067$ & 0,862 \\
\hline
\end{tabular}

Selain itu, dilakukan analisis juga terhadap QC berupa crossplot antara nilai impedansi akustik hasil inversi dengan nilai akudasi akustik data log sumur pada lokasi sumur. Hasil dapat dilihat pada Tabel 2.

Hasil antara model-based Soft Constraint dan Model Hard Soft Constraint memiliki hasil inversi yang cukup baik. Namun model-based Constraint memiliki nilai yang baik pada kuantitas error, Correlation, Err. Sythentics \& Seismic, dan nilai least square dari impedansi hasil inversi dan impedansi sumur yang baik. Hasil penampang impedansi akustik dapat dilihat pada Gambar 5 .

Sehingga metode inversi model-based Hard Constraint dipilih sebagai parameter penentuan dalam pembuatan inversi impedansi akustik. Dari penampang hasil inversi, impedansi akustik memiliki hasil yang terbaik sesuai yang disajikan Gambar 6 .

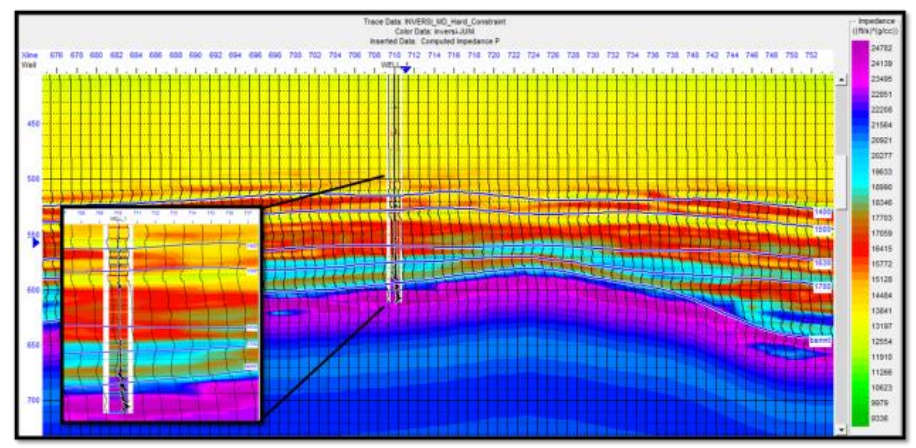

Gambar 5. Penampang impedansi akustik hasil optimasi parameter. 


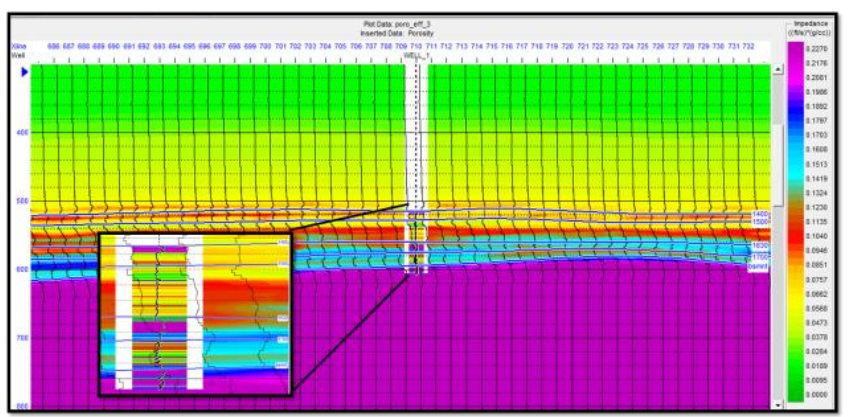

Gambar 6. Penampang porositas dengan pendekatan persamaan impedansi akustik.

Hasil crossplot antara porositas dan impedansi akustik, digunakan untuk mencari persamaan antara hubungan porositas dan impedansi. Impedansi akustik telah didapatkan dari hasil inversi yang telah dilakukan. Adapun persamaan porositas yang didapatkan adalah $y=-0,00000557801 x+$ 0,748735 yang selanjutnya dipergunakan untuk mentransformasi penampang impedansi akustik yang sudah ada ke dalam porositas yang dapat dilihat pada Gambar 7.

Hasil dari slicing impedansi akustik yang ditunjukan pada Gambar 9, maka bisa terlihat bahwa impedansi akustik yang tinggi berada di aerah ketinggian. Sehingga zona batuan pasir dapat terlihat pada impedansi akustik yang bernilai tinggi sesuai Gambar 8 .

Selain itu, terlihat pada slicing porositas pada Gambar 8, bahwa daerah tinggian memiliki nilai porositas efektif yang tinggi juga. Nilai porositas yang dianggap memiliki porositas baik ditunjukkan dengan nilai porositas 0,125 atau $12,5 \%$. Pada penampang porositas tersebut dapat diobservasi nilai porositas yang lebih besar dari 12,5\% ditunjukkan dengan warna merah hingga ungu.

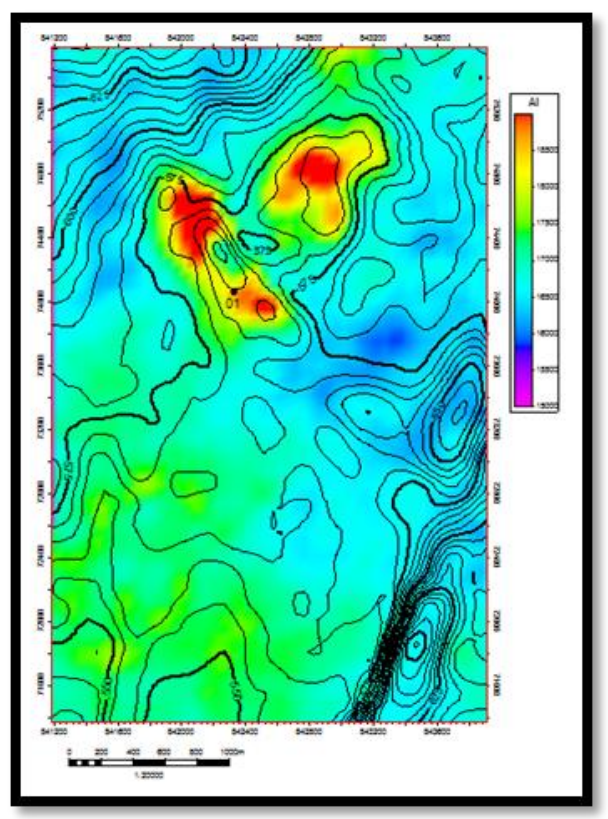

Gambar 7. Slicing impedansi akustik pada horison 1630 per time. 


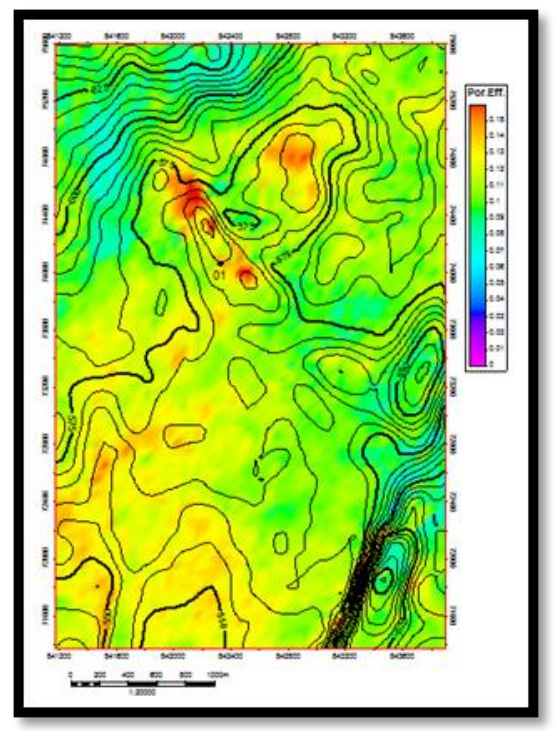

Gambar 8. Slicing porositas pada horison 1630 per time

\section{Kesimpulan dan Saran}

\section{Kesimpulan}

1. Analisis crossplot Gamma-Ray dan p-impedance dapat membedakan litologi sand dan shale pada zona target.

2. Dalam mengkarakterisasi batuan pasir, metode seismik akustik impedansi ini dapa memberikan hasil yang lebih baik daripada menggunakan seismic aplitudo biasa.

3. penetuan nilai maksimal dari eror dan korelasi dari ketersediaan data yang ada, memberikan hasil volum impedansi akustik yang paling maksimal yang dapat dihasilkan.

4. Penyebaran batuan pasir pada zona target dari peta akustik impedansi dan porositas, menunjukkan konsistensi yang baik.

\section{Saran}

Dikarenakan hanya satu sumur yang dapat digunakan dalam penelitian ini, disarankan menambahkan data sumur untuk mendapatkan hasil karakterisasi dan deliniasi yang lebih baik baik serta lebih presisi. Dengan penambahan data sumur, dapat di aplikasikan metode lain seperti multi atribute yang dapat digunakan sebagai pembanding dan menambah informasi agar karakterisasi reservoir lebih konklusif.

\section{Daftar Rujukan}

[1] Ginger, D., and K. Fielding, 2005, The petroleum systems and future potential of the South Sumatra Basin: Proceedings Indonesian Petroleum Association 30th Annual Convention, p. 6789.

[2] Sukmono,S., 2002, AI Inversion \& Its Application in Time-Lapse Analysis.

[3] Sukmono, S., 2006, Seismic Inversion \& AVO Analysis for Reservoir Characterization, Laboratorium Geofisika Reservoar, Program Studi Teknik Geofisika, Institut Teknologi Bandung.

[4] Cooke, D., and Cant, J., 2010, Model-based Seismic Inversion:Comparing deterministic and probabilistic approaches: CSEG Recorder, vol April 2010, P. 28 - 39

[5] Yilmaz, O., 2006, Seismic data analysis: processing, Inversion and Interpretation of seismic data: Society of exploration geophysics, p. 1793-1999.

[6] Connolly, P. A., 2010, Robust workflows for seismic reservoir characterization: SEG Distinguished Lecture.

[7] Chopra, S., J. P. Castagna, and Y. Xu, 2009, Thin-bed reflectivity inversion and some applications: First Break, 31, 27-34 
[8] Meijuan, J, Kyle, T.S., 2016, Rock Physics and Seismic-Inversion Based Reservoir Characterization of the Haynesville Shale, Geophysical Research Institute.

[9] Hossain, Z., and T. Mukerji, 2011, Statistical rock physics and Monte Carlo Simulation of seismic attributes for greensand: 73rd Annual International Conference and Exhibition, EAGE. 